\title{
HISTÓRIAS DE TRANSFORMAÇÃO NAS VIDAS DOS USUÁRIOS DO PROGRAMA SEGUNDO TEMPO (PST) DE JABOATÃO DOS GUARARAPES, PERNAMBUCO
}

\section{STORIES OF TRANSFORMATION IN THE LIVES OF USERS OF THE SECOND TIME PROGRAM (PST) DE JABOATÃO DOS GUARARAPES, PERNAMBUCO}

\author{
Marcus Vinicius Sanchez Lima', Thiago Vasconcellos Modenesi²
}

Submetido em: 26/06/2018

Correções requeridas em: $28 / 04 / 2020$

Aprovado em: 14/09/2020

\section{RESUMO}

A presente pesquisa que se insere nos estudos de abordagem qualitativa na área da Educação Física, toma como foco central as questões relacionadas ao Programa Segundo Tempo desenvolvido no município de Jaboatão dos Guararapes. Visamos aqui responder ao problema de pesquisa em que discutimos como as vivências em programas sociais se caracterizam nas contribuições que possam ter um cunho transformador, isso feito a partir da literatura e das entrevistas realizadas, onde estas possam evidenciar este caráter mudancista. $O$ debate pretende contribuir com uma leitura mais refinada das políticas públicas de esporte e lazer construídas a partir da eleição do presidente Luís Ignácio Lula da Silva, através de algumas reflexões, conceitos e procedimentos metodológicos, que constituem parte fundamental das ferramentas de pesquisa do pesquisador social, particularmente aqueles que buscam uma leitura sociocultural do esporte, do lazer e das temáticas correlatas. Para tanto utilizamos alguns autores do campo científico/acadêmico da Educação Física, bem como recorremos a alguns agentes de outras áreas do conhecimento, que com suas contribuições fundamentam o universo pesquisado.

PALAVRAS-CHAVE: Políticas Públicas. Esportes Educacional. Transformação Social.

\section{ABSTRACT}

The present research that is inserted in the studies of qualitative approach in the area of Physical Education takes as central focus questions related to the Second Time program developed in the municipality of Jaboatão dos Guararapes. We aim here to answer the research problem in which we discuss how the experiences in social programs are characterized in the contributions that can have a transforming character, this done from the literature and interviews conducted, where these can evidence this character of change. The debate aims to contribute to more refined reading of public sports and leisure politics built after the election of President Luís Ignácio Lula da Silva, through some reflections, concepts and methodological procedures, which are a fundamental part of the social researcher's research tools, particularly those who seek a sociocultural reading of sports, leisure and related themes. For this, we use some authors of the scientific/academic field of Physical Education, as well as we resort to some agents of other areas of knowledge, who with their contributions ground the universe researched.

KEYWORDS: Public Politics. Educacional Sports. Social Transformation.

\footnotetext{
${ }^{1}$ Especialista em Gestão Pública, ex-Secretário de Esporte de Jaboatão dos Guararapes, Pernambuco. Correio eletrônico: marquinhos.sanchez@gmail.com.

2 Professor de Graduações da Uninabuco, professor Titular do Mestrado em Inovação e Desenvolvimento da UNIFG e professor colaborador do Mestrado em Gestão Pública da UFPE. http://orcid.org/0000-0002-8628-0300. Correio eletrônico: thiagomodenesi@hotmail.com
} 


\section{INTRODUÇÃO}

O Segundo Tempo é um programa que se originou no Ministério do Esporte, voltado para crianças, adolescentes e jovens entre 6 e 17 anos, estudantes da rede pública de ensino e em áreas expostas a riscos sociais. O Programa Segundo Tempo (PST) é a política pública de maior envergadura na democratização do acesso ao esporte, tanto na quantidade de recursos destinados, mas também no volume de projetos e pessoas atendidas (SOUSA et al, 2010)

O mesmo é uma política pública construída a partir do primeiro governo do Presidente Lula e sofreu adaptações, ampliações e adequações em todos os governos que vieram na sua sequência, mostrando sua perenidade e vigor, no período por nós estudado era um programa estratégico do governo federal que teve por objetivo democratizar o acesso à prática e à cultura do esporte, de maneira que promovesse o desenvolvimento integral de crianças, adolescentes e jovens como fator de formação da cidadania e melhoria da qualidade de vida, principalmente dos que se encontram em áreas de vulnerabilidade social

Logo em seu princípio, desde sua elaboração, teve canais de ligação com as universidades federais, passando na sequência a ser implementado nos espaços físicos das mesmas e dialogando com seus arredores e alunos também, espraiando-se posteriormente para os governos estaduais e municipais.

O Programa foi criado em 2003 e desde então já atendeu mais de cinco milhões de crianças e jovens em todo o País. Tornada referência internacional em termos de política social, o PST amplia as atividades pedagógicas para o contra turno escolar, garantindo reforço alimentar, reforço escolar e atividades esportivas.

Os princípios que norteiam o Programa buscam a inclusão social, a vivência junto a diversidade humana, o aprimoramento da consciência cidadã e o exercício da democracia, através da realização de práticas pedagógicas calcadas no esporte educacional, este é entendido aqui como propiciador de consciência saudável via práticas sociais que envolvam temas lúdicos da cultura corporal, com sentidos e significados para quem os pratica (LORENZINI, BARROS e SANTOS, 2010).

Segundo o que consta no documento da Política Nacional do Esporte (PNE), O Ministério do Esporte estabelece ligações com um universo composto de crian- ças, jovens, adolescentes, adultos, idosos, com pessoas com deficiências ou com necessidades educativas especiais, com o sistema esportivo nacional e com o sistema educacional brasileiro que articula a educação básica e superior.

A relevância desse universo, levando-se em consideração sua complexidade, amplitude e heterogeneidade, exige do Ministério uma responsabilidade social, que deve se concretizar em ações balizadas, rigorosamente, por princípios humanísticos fundamentais, inequivocamente democráticos (BRASIL, 2005).

O Programa incentiva o esporte como fator de desenvolvimento da cidadania e da melhoria da qualidade de vida. Busca através de práticas esportivas educacionais aperfeiçoar suas capacidades físicas e habilidades motoras, melhorar a autoestima e cooperar para a redução da exposição aos riscos sociais (drogas, prostituição, gravidez precoce, criminalidade e trabalho infantil).

Sendo assim, o esporte educacional deve ser compreendido para além de sua forma institucionalizada, ou seja, como toda e qualquer forma de atividade física que contribua para a aptidão física, o bem-estar mental, a interação, a inclusão social e o exercício da cidadania.

Consequentemente, assume como elementos indissociáveis de seu propósito pedagógico as atividades de lazer, recreação, práticas esportivas sistemáticas e/ ou assistemáticas, modalidades esportivas e jogos ou práticas corporais lúdicas da cultura brasileira, de forma a possibilitar ampla vivência e formação humana e de cidadania, sobretudo de crianças, adolescentes e jovens.

O Programa Segundo Tempo, desde a sua criação, vem pautando suas ações na concepção de uma sociedade igualitária, em qual todas as pessoas devem ter o direito de acesso aos elementos fundamentais para o desenvolvimento humano, usando o esporte como um desses elementos, na constituição de suas intervenções com foco para crianças, adolescentes e jovens que estão em situação de risco social.

Assim, para efetivarmos uma inclusão verdadeira pelo esporte, deveremos buscar assumir novos olhares sobre todos os corpos, deficientes ou não, e não exaltar tanto a dificuldade que se observa, mas principalmente as potencialidades que cada um tem para se expressar. Se desejamos implantar uma prática esportiva para todos, a partir de uma visão ampla do que seja corpo e suas capacidades de expressão, essa é a forma mais cientifica e sensível socialmente de fazê-lo. 
Entendendo uma política pública de qualidade como um dos caminhos para a democratização do esporte, a articulação entre o sistema educacional e o sistema esportivo, é indispensável para assegurar a ampliação da participação de estudantes de todos os níveis de ensino, em atividades e eventos esportivos.

No Programa Segundo Tempo, as oportunidades devem sempre serem criadas. As ações pedagógicas precisam traduzir uma concepção do esporte plural e devem também se valer de estratégias que garantam a participação de todos.

A intervenção profissional deve ser também orientada, fundamentada e permanentemente avaliada, para que de fato possam transformar a realidade social e o futuro da população, um dos enfoques do projeto.

O esporte na dimensão aqui proposta não pode ser visto como algo que é um legado para poucos ou apenas para algumas parcelas da nossa população, é preciso ir para além disso buscando aplicar o mais próximo do plenamente o que o PST se propõe a ser.

O esporte precisa ganhar na vida cotidiana a dimensão que lhe permite a Constituição do nosso país: como um direito. Assim como temos o direito à moradia, direito à saúde, o direito à educação, o direito à previdência social, o direito ao trabalho.

Assim como temos um conjunto de direitos, vários deles mais avançados seja na dimensão das políticas públicas ou na própria percepção da população, o esporte tem de assegurar o seu papel no processo de desenvolvimento humano, no processo de desenvolvimento do nosso país e na busca da garantia do bem-estar e da qualidade de vida.

Se enxergamos o esporte a partir de uma visão sistêmica, que assume a missão da universalização e que se impõe o desafio do acesso, que se coloca o desafio de ser um direito social, é preciso discutir, de um lado, o papel da escola e, de outro, o papel social dos clubes esportivos, muitos deles sucateados ou então fechados em si mesmos, ou seja, com seus altos muros, se resumindo aos seus praticantes ou associados que podem pagar por aquele acesso.

É preciso discutir o papel que têm, nesse sistema, o sistema confederativo, as federações, a formação de atletas e os próprios atletas. É preciso discutir, a partir dessa visão sistêmica já aqui citada, o papel que tem o esporte como aliado de um projeto de Brasil que se desenvolve economicamente, que se desenvolve na in- fraestrutura e que se desenvolve do ponto de vista humano, que se desenvolve para o seu povo.

Se o certo é partir dessas premissas aqui listadas, e se é certo considerar que a escola tem papel determinante nisso, considerar que esse sistema se estruture a partir da escola e do diálogo a partir dessa, é preciso discutir o papel que tem a União, o papel que tem o Estado brasileiro no fomento e no desenvolvimento do esporte, possibilitando o acesso à sua prática em espaços variados adequados e com qualidade para toda uma geração. Esse desafio, embora hoje possa trazer inúmeros resultados, acreditamos que seja um desafio em construção, em permanente construção, parte articulada a políticas públicas mais gerais.

Sendo assim, nosso artigo busca aqui apresentar as contribuições do Programa Segundo Tempo - PST que tem possibilitado a transformação na vida de seus beneficiários, nos mais diversos aspectos, esse é nosso objetivo geral que aqui perseguimos.

Para vencê-lo passamos a discutir a seguir como a prática de atividades esportivas do PST influência o rendimento escolar e esportivo, a socialização e a autoestima, isso configurando nossos objetivos específicos de pesquisa.

Esse conjunto é aqui estudado a partir do caso específico da implantação e análise do Programa na cidade de Jaboatão dos Guararapes, situada no Estado de Pernambuco, que acompanhou a iniciativa desde seu nascedouro no Governo Federal, analisamos efetivamente esta ação na cidade de 2012 até 2016, período no qual os autores foram ambos secretários de esporte.

\section{CONVÊNIO COM JABOATÃO DOS GUARARAPES, PERNAMBUCO}

O Programa Segundo Tempo desenvolvido no município de Jaboatão dos Guararapes surge a partir da necessidade de uma política pública na área de esporte de que venha consolidar princípios básicos que a gestão entende que precisam ser combatidos que são a vulnerabilidade social e o esporte e lazer com o direito social.

Dessa forma, desenvolver uma política que tenha perenidade, implicando na definição de um planejamento continuado, com iniciativas sistemáticas e eventos pontuais, são iniciativas fundamentais para uma ação que tem como intencionalidade o combate a situações de risco e vulnerabilidade da população. 
Percebendo o esporte como parte integrante da educação, onde as crianças e os adolescentes aprendem na prática dos mesmos valores éticos e morais, têm lições de cidadania, assimilam o respeito as diferenças, entendemos este ser de fundamental importância para o desenvolvimento social.

As atividades do Programa ocorrem em ambientes da escola ou espaços comunitários públicos ou privados sem fins lucrativos, que possuem parceria com a Secretaria Executiva de Esporte do município de Jaboatão dos Guararapes, cada um de seus núcleos com até 100 participantes.

Nestes núcleos as atividades acontecem no contra turno escolar ocupando o tempo ocioso das crianças, adolescentes e jovens. As aulas são ministradas por um coordenador de núcleo (profissional de nível superior da área de Educação Física) e um monitor (estudante do curso de Educação Física), que trabalham atividades esportivas individuais (ginástica, atletismo, lutas entre outras), coletivas (handebol, futebol, voleibol entre outras) e complementares (participação de eventos, apresentação de trabalhos entre outros).

O Programa Segundo Tempo - PST teve seu início em Jaboatão dos Guararapes no mês de setembro do ano de 2012. Até o período por nós estudado, no caso o ano de 2016, contava com 104 núcleos ativos, pertencentes a 7 setoriais: Jaboatão Centro, Cavaleiro, Curado, Muribeca, Prazeres, Praias e Guararapes, seguindo a estrutura administrativa da cidade.

As atividades esportivas oferecidas no Programa Segundo Tempo possuem o caráter educacional, tendo como objetivo o desenvolvimento integral da criança e do adolescente, de forma a favorecer a consciência de seu próprio corpo, explorar seus limites, aumentar as suas potencialidades, desenvolver seu espírito de solidariedade, de cooperação mútua e de respeito pelo coletivo.

Tais dados são fruto da participação dos autores enquanto secretários de esporte durante o período estudado neste artigo, participação nas atividades aqui elencadas, bem como da análise dos relatórios da equipe da Secretaria de Esporte da cidade de Jaboatão dos Guararapes, no período de 2012 a 2016.

A estrutura do Programa Segundo Tempo está assim apresentada na cidade de Jaboatão dos Guararapes, Pernambuco:

- Atividades são desenvolvidas no contra turno escolar para os beneficiados, em espaços físicos específicos às atividades esportivas a serem desenvolvidas, podendo ser no ambiente da escola ou espaços comunitários (públicos ou privados);

- Oferta a cada beneficiado de, no mínimo, 3 modalidades esportivas (2 coletivas e 1 individual) até os 15 anos completos e a partir desta idade a possibilidade de se ofertar apenas uma modalidade, de acordo com o interesse do beneficiado;

- Oferta a cada beneficiado de atividades esportivas com frequência mínima de 2 vezes na semana, e de 3 horas diárias ou 3 vezes na semana, e de 2 horas diárias;

São exemplos de modalidades desenvolvidas nos núcleos:

a). Coletivas: Futebol de Campo, Futsal, Voleibol, Handebol, Basquete e Rugby.

b). Individuais: Xadrez, Atletismo, Capoeira, Lutas, Natação, Dança, Ginástica Rítmica.

Para o desenvolvimento das atividades são distribuídos em parceria com o ME, Kits esportivos e Kit de uniformes, para dar suporte. Seguem os resultados esperados e os impactos diretos do PST:

- Melhoria no convívio e na integração social dos participantes;

- Melhoria da autoestima dos participantes;

- Melhoria das capacidades e habilidades motoras dos participantes;

- Melhoria das condições de saúde dos participantes;

- Aumento do número de praticantes de atividades esportivas educacionais; e

- Melhoria da qualificação dos profissionais envolvidos. Impactos Indiretos

- Diminuição da exposição dos participantes a riscos sociais;

- Melhoria no rendimento escolar dos alunos envolvidos; - Diminuição da evasão escolar nas escolas atendidas; - Geração de novos empregos no setor de educação física e esporte nos locais de abrangência do programa;

- Melhoria da infraestrutura esportiva no sistema de ensino público do País e nas comunidades em geral.

\section{A PRÁTICA DA LIBERDADE}

Ao tratarmos aqui de uma educação que valoriza o pensamento crítico e a participação do sujeito no seu processo de aprendizagem, sem que ele apenas reproduza apenas o que o professor manda, "como uma situ- 
ação gnosiológica, desafia-os a pensar o corretamente e não o memorizar" (FREIRE, 1980), estamos dando ênfase e reforçando a autonomia do sujeito frente suas decisões e responsabilidades, configurando assim a transição de um aluno reprodutor, para um aluno ator.

[...] a proposta de ensino que aqui se apresenta fundamenta-se na cultura corporal como objeto de estudo e ensino da Educação Física, cuja ação pedagógica deve estimular a ação-reflexão-nova ação sobre o acervo de formas e representações do mundo que o ser humano tem produzido, exteriorizadas pela expressão corporal em jogo, dança, luta, ginástica e esporte. (COLETIVO DE AUTORES, 1992; 2012, p. 5).

Também é importante destacar que toda atitude tem uma finalidade por fim, tudo é intencional, cabe ao professor junto aos alunos articular as tais situações em que haverá as problematizações para a construção do conhecimento.

Devido a isso é de fundamental importância estarmos sempre atentos ao contexto dos atores em que o professor/educador/mestre irá trabalhar, pois ele vai se deparar com inúmeros contextos sociais, históricos, psicológicos, assim como "não há educação fora das sociedades humanas e não há homem no vazio", (FREIRE, 1967, p.35) todos devem ser respeitados e trabalhados na perspectiva da humanização sempre.

Reconhecer o Programa segundo Tempo como prática social, é assegurar sempre que sua prática extrapole os limites do trabalho para o esporte educacional, é compreender que sua prática, quando humanizadora, alimenta de maneira destacada as inquietações e anseios do ser humano, levando-o a refletir sua prática social, seu empoderamento frente as contradições e dialéticas da sua vida, o direito ao corpo e a expressão do mesmo, a expressividade sensível criadora de ação-reflexão-ação.

\section{PROCEDIMENTOS METODOLÓGICOS}

\subsection{Ação Crítico-Superadora}

Como dissemos, as intervenções acontecem desde 2012 no município de Jaboatão dos Guararapes e a Secretaria de Esporte deu todo o suporte para a realiza- ção deste estudo que aqui fazemos no acompanhamento das intervenções.

Entendendo que fundamentalmente as atividades desenvolvidas pelo Programa Segundo Tempo tem um cunho libertador devemos sempre levar em consideração os princípios da metodologia crítico-superadora que valoriza aspectos importantes da cultura corporal estreitando laços entre professor-aluno e favorecendo o dinamismo de realidades em busca de objetivos comuns.

Para isso, alguns critérios são de fundamental importância para que haja fluidez permanente na vivência metodológica, um deles é sem dúvida a alteração da relação de poder, neste caso, o professor se põe no lugar de ator junto aos alunos, construindo a prática com e para eles, ou seja, caracterizando uma construção dada aqui de maneira coletiva e não atuando numa "educação bancária" em que o professor apenas deposita o conhecimento no aluno (FREIRE, 1983).

Outro elemento fundamental é a alteração da comunicação e linguagem, isso implica a capacidade do professor em articular as mais diversas formas de transmissão das informações para os alunos, adequando-se as realidades das pessoas com o que ele está trabaIhando. Para isso é basilar que ele busque ser empático com os alunos e tente compreender o mais plenamente possível as suas realidades, pondo-se no lugar do outro.

Nem todos os alunos são iguais, portanto, é necessário respeitar-se o tempo pedagógico de cada um, cabe ao professor ligar situações junto ao aluno para que ele possa superar suas próprias dificuldades configurando-se em:

[...] uma cultura corporal dialética, importa-se com o que está se refere, aliás, está sócio e politicamente referenciada, circunscrita às suas condições objetivas, concretas, pois diz respeito a uma produção humana, uma atividade humana, fruto de seu trabalho [...]. (COLETIVO DE AUTORES, 1992; 2012, p. 7).

O trato do conhecimento é mais um fundamento importante que o professor deve se apropriar metodologicamente de maneira frequente, principalmente para saber o que, como e porque trabalhar determinados conteúdos, desse modo, o direcionamento das aulas será o adequado para as necessidades de cada grupo.

Para poder materializar os dados das intervenções 
utilizamos os conceitos chaves da etnometodologia e da pesquisa-ação na qual o professor/pesquisador obtém os dados na própria práxis sem se distanciar de seu objeto de intervenção.

- Análise de história oral;

- Aplicação de questionários semiestruturados;

- Seleção do CORPUS para análise percepção da mudança.

Foram escolhidos por nós oito casos relevantes que serão analisados sob quatro perspectivas: pais, escola, professor do Programa e beneficiário.

\subsection{A Etnografia}

A nossa segunda opção metodológica, a etnografia, foi se delineando exatamente pelos contornos que iam sendo visualizados no desenrolar das análises da primeira fase do estudo, que só recentemente surgiu na literatura educacional.

A etnografia pode ser definida como a descrição de um sistema de significados culturais de um determinado grupo, na qual Geertz coloca como sua tarefa principal a descrição profunda. As diferentes formas de entender cultura na perspectiva etnográfica baseiam-se igualmente nos significados partilhados, pois é a cultura que permite às pessoas agirem conjuntamente (BOGDAN e BIKLEN, 1994)

Os critérios para a utilização da abordagem etnográfica nas pesquisas escolares foram resumidos por Firestone e Dawson, no ano de 1981, e apresentados por Lüdke e André (1986, p. 14) e dentre eles destacamos alguns que iluminaram nossa investigação. O problema a ser redescoberto num determinado campo parece ser uma constante e uma realidade nesse tipo de pesquisa.

Contudo, com a evolução da base teórica na qual nos apoiamos inicialmente - a pedagogia de Paulo Freire - e a definição de uma teoria de sustentação do nosso trabalho, a teoria crítica, sentimos que faltava à etnografia uma perspectiva metodologicamente mais crítica, inquietação que fez com que buscássemos novos enfoques sobre a etnografia, surgindo a partir daí uma maior tranquilidade com a perspectiva da etnografia crítica apresentada por Jim Thomas (1993), elegida como a mais viável ao nosso propósito.

Definida por esse autor como um tipo de reflexão que examina a cultura, conhecimento e ação, a etnografia crítica expande os nossos horizontes para escolhas e amplia a nossa capacidade experimental de ver, ouvir e de sentir, aprofundando e enfatizando compromissos éticos, forçando-nos a desenvolver e agir sob valores comprometidos com agendas políticas (BOGDAN e BIKLEN, p. 2).

Os etnógrafos críticos, portanto, descrevem, analisam e abrem um olhar examinador aos aspectos escondidos, centros de poder e hipóteses que podem inibir, reprimir e constranger, o que requer uma sabedoria crítica para que as compreensões do senso comum sejam questionadas.

Nessa direção, Thomas (op. cit., p. 26) apresenta a perspectiva de uma etnografia participante em diferentes concepções, entre elas, a vertente influenciada pela teoria de Paulo Freire (1987), na qual o papel da reflexão-ação é primordial para a transformação do mundo.

Foi com esse novo olhar sobre a etnografia que ultrapassa a visão de apenas aprender o significado que as pessoas dão às coisas e aos fatos, e vai além, com a ampliação, pela reflexão, de perceber as possibilidades alternativas com objetivos emancipatórios, que adentramos o contexto da pesquisa.

\subsection{Técnicas de Pesquisa e suas etapas}

O estudo por nós aqui realizado foi conduzido em três fases. Na primeira fase, foram realizadas várias atividades preparativas para a realização da pesquisa: contatos preliminares com gestores das escolas, coordenadores de núcleo, beneficiários do programa, pais de beneficiários a serem entrevistadas, elaboração do protocolo de pesquisa e diário de campo e a preparação dos instrumentos de coleta de dados.

$\mathrm{Na}$ segunda fase a coleta de dados foi realizada por meio de observação participante, aplicação de questionários e entrevistas. Na terceira fase, os dados coletados foram analisados através da análise de conteúdo.

A tabela 1 sintetiza as etapas previstas, associando cada uma com seus objetivos e técnicas empregadas para sua realização. 
Tabela 1: Etapas, objetivos e técnicas da pesquisa

\begin{tabular}{|c|c|c|}
\hline ETAPA & OBJETIVOS DAETAPA & TÉCNICAS EMPREGADAS \\
\hline $\begin{array}{l}\text { PRIMEIRA - ATIVIDADES PRELIMINARES } \\
\text { A) CONTATOS PRELIMINARES COM } \\
\text { GESTORES DA ESCOLA, COORDENADORES } \\
\text { DE NÚCLEO E BENEFICIÁRIOS E PAIS DE } \\
\text { ALUNOS. } \\
\text { B) SELEÇÃO DE RESPONDENTES. } \\
\text { C) ELABORAÇÄO DO PROTOCOLO DE } \\
\text { PESQUISA E DO DIÄRIO DE CAMPO. } \\
\text { D) PREPARAÇÃO DOS INSTRUMENTOS DE } \\
\text { COLETA DE DADOS. }\end{array}$ & $\begin{array}{l}\text { SOLICTARA AUTORIZAÇÕES PARA CONDUÇÃO } \\
\text { DO ESTUDO } \\
\text { SELECIONAR PESSOAS A SEREM } \\
\text { ENTREVISTADASIRESPONDENTES. } \\
\text { ESTABELECER UM PLANO DE COLETAE } \\
\text { ANÁLISE DE DADOS. } \\
\text { CONSTRUIR QUESTÕES OU TÓPICOS PARAAS } \\
\text { ENTREVISTAS. }\end{array}$ & $\begin{array}{l}\text { ENTREVISTAS NÃO } \\
\text { ESTRUTURADAS. }\end{array}$ \\
\hline $\begin{array}{l}\text { SEGUNDA - COLETA DE DADOS } \\
\text { A) APLICAÇÃO DE QUESTIONÁRIOS } \\
\text { B) INTERVENÇÃO } \\
\text { C) OBSERVAÇÃO } \\
\text { D) ENTREVISTAS PESSOAIS }\end{array}$ & $\begin{array}{l}\text { LEVANTAR EVIDÉNCIAS E CONSTRUIR BANCO } \\
\text { DE DADOS PARA ANÁlLSE. }\end{array}$ & $\begin{array}{l}\text { QUESTIONȦRIOS. } \\
\text { OBSERVAÇÄO PARTICIPANTE. } \\
\text { ENTREVISTAS PARCIALMENTE } \\
\text { ESTRUTURADAS. }\end{array}$ \\
\hline $\begin{array}{l}\text { TERCEIRA-ANÁLISE DE DADOS } \\
\text { A) TABULAÇÃO DOS DADOS } \\
\text { B) TRANSCRIÇÃO } \\
\text { C) CODIFICAÇÃO, CATEGORIZAÇÃO E } \\
\text { INTERPRETAÇÄO } \\
\text { D) RESULTADOS ENCONTRADOS }\end{array}$ & $\begin{array}{l}\text { EXAMINAR, CATEGORIZAR, CLASSIFICARE E } \\
\text { RECOMBINAR EVIDÊNCIAS. }\end{array}$ & $\begin{array}{l}\text { ANÁLISE ESTATISTICA } \\
\text { DESCRITIVA. } \\
\text { ANÁLISE DE CONTEÚDO. }\end{array}$ \\
\hline
\end{tabular}

Tais etapas não seguiram necessariamente essa sequência, da primeira para a segunda e assim sucessivamente. A transcrição de cada entrevista, por exemplo, foi realizada após a realização da mesma, sem que se espere pela conclusão das demais.

\section{POLÍTICAS PÚBLICAS NA PERSPECTIVA DE UM OLHAR TRANSFORMADOR}

Os estudos acerca das políticas públicas relacionadas às práticas corporais e esportivas, enquanto parte constitutiva de uma Política Educacional, na sua grande maioria, tem privilegiado quase sempre o setor escolar como seu principal campo de investigação. As pesquisas sobre esse tema que aqui pesquisamos, geralmente se prestam apenas a analisar as propostas curriculares para o ensino da Educação Física

A construção de uma Educação Física, e do Esporte e Lazer enquanto um tipo de política pública sintonizada com um projeto político-social em defesa dos interesses das classes populares, só aconteceu plenamente mais recentemente, com o processo de redemocratização do país instalado nos anos 80 do século XX.

Nessa década, a partir da derrocada do regime militar brasileiro, passamos a vislumbrar no cenário político a ascensão às administrações públicas das forças sociais que haviam se organizado na luta pela redemocratização do país e em defesa dos interesses da maioria da população, estas traziam construções e propostas de políticas públicas mais calcadas no atendimento dos que se encontravam em situações mais vulneráveis.

Dentre os vários Estados da federação que elegeram governos comprometidos com a luta dos setores populares estava Pernambuco, que, durante dois períodos (1987-1990/1995-1998) foi administrado pela coligação de partidos denominada de Frente Popular de Pernambuco, tendo à frente já falecido governador Miguel Arraes de Alencar.

Nessa coalizão, as alianças formadas atenderam a representação de setores populares que, por sua vez, puderam influenciar na definição de políticas sociais mais comprometidas com os interesses da maioria.

Segundo Weber (1991), a volta de Arraes à cena política pernambucana, aconteceu num contexto ali demarcado pelo movimento de democratização do país, o que impulsionou o aprofundamento do debate acerca da concepção de Estado, dos interesses sociais nele contidos, na relação entre sociedade civil e sociedade política, na noção de governo como instrumento de concretização de projetos político-sociais de classe e frações de classe e na intensificação da luta pela democracia, realizada por diversas organizações da sociedade civil.

Nessa quadra, Miguel Arraes foi eleito "como representante de um projeto político-social no qual os interesses e necessidades da maioria da população constituíam o eixo principal". Dessa forma, o governo de Pernambuco teve como princípios norteadores da sua gestão a "Democratização" e o exercício da "Cidadania" (WEBER, 1991, p.17).

Desta forma, as diretrizes das ações do primeiro governo Arraes (1987-1990), materializava o debate acadêmico sobre a educação, estabelecido nacionalmente e as demandas dos diferentes segmentos sociais, expressos nos diversos documentos apresentados ao governo durante o período eleitoral, bem como pela composição do seu secretariado.

No que tange à Educação Física, Esporte e Lazer, a política implementada pelo governo popular de Pernambuco (1987-1990), possibilitou importantes alterações na cultura de ensino da Educação Física.

Ressaltamos que tais mudanças aconteceram em sintonia e impulsionadas pelos movimentos de resistência contra o autoritarismo do regime militar e pela redemocratização da sociedade brasileira, ao mesmo tempo que incorporaram alguns elementos do debate teórico acumulado na Educação e nas Ciências Sociais e Humanas no seu conjunto, dos finais dos anos 70 a mea- 
dos da década de 80 do século XX.

Isso posto, uma política pública de esporte necessita sempre apresentar uma concepção de prática esportiva que se proponha a superar o modelo do esporte de alto-rendimento e suas manifestações nas escolas e na comunidade. Na ótica de um dos seus principais teóricos:

[...] o tratamento dado ao Esporte na Escola, tem sido, ainda, pautado pela ação reprodutora dos valores, princípios e procedimentos próprios do "Esporte de Rendimento", do "Esporte de Alto Nível", adotando, dentre outros equívocos, as conhecidas competições esportivas escolares, como eventos isolados, desvinculados do processo educativo com a finalidade de revelar talentos esportivos.[...] Essa prática repressivo-alienante tem conduzido ao reforço da concepção dualística de homem, na qual a pretensa dicotomia corpo/ mente encontra sua disseminação[...] (BARBIERI, 1996, p.23).

Continuando sua crítica, o autor aqui aponta que o caráter repressivo-alienante do esporte de alto nível está associado ao fato deste caracterizar-se pelo "estimulo à prática associada às recompensas extrínsecas" - onde a busca da vitória a qualquer custo é geradora da violência, da fraude e do doping; pela "rígida hierarquia" - que leva os alunos a apenas receber ordens do professor/técnico; pela "discriminação da mulher"; pela "hiper-seletividade" - em função da conotação finalística das competições esportivas, rotulando a maioria de crianças e adolescentes como não-talentosos e pela "violência simbólica" - configurada, principalmente, na tentativa de tornar os alunos "atletas" sob condições extremamente desiguais, as quais os mesmos estão submetidos (CF. BARBIERI, 1996, p. 23-24).

Refletir acerca de políticas públicas a partir de uma experiência que aconteceu dentro de uma não-operacionalização de uma dimensão setorial de educação é uma tarefa difícil. Inicialmente, pela própria complexidade de entendimento do termo Política Pública e, posteriormente, pelo distanciamento que existe entre o que está elaborado e projetado e o que vem a ser efetivamente operacionalizado.

No que se refere ao entendimento, constatamos que, no campo teórico, as discussões não se tornam menos complexas ao passar dos anos, pois a literatura pertinente é sempre enfática ao reconhecer o modo heterogêneo e ambíguo como se classificam os vários autores na pluralidade de abordagens teórico-metodológicas existentes sobre as políticas de esporte.

Ao tratarmos de uma conceituação, é importante considerar dois planos: um mais abstrato e outro mais concreto. No primeiro, o Estado se apresenta como o locus onde se condensa o tecido social, tendo aqui presente as estruturas de poder, de dominação e os conflitos; no segundo a máquina governamental é o seu principal referente, em que se considera os recursos de poder em que operam na sua definição.

Sendo assim, as políticas públicas em que materializam o Estado, ou seja, estas se tornam o Estado em ação. Investigando como se deu o surgimento de uma política pública, podemos afirmar que esta deve ter origem numa questão que se torna socialmente problematizada e que exige atuação do Estado.

No entanto, é possível reconhecer, também, que a construção de uma teoria acerca da Educação Física na perspectiva crítico-superadora faz parte de um movimento bem mais amplo da produção do conhecimento na área ao nível nacional, portanto, influenciando também as políticas públicas sobre a temática.

\section{ANÁLISE DE DADOS}

Levantados os documentos e realizadas as transcrições das gravações que registraram os depoimentos dos atores entrevistados, passamos à organização e interpretação dos dados. Para tanto, procuramos seguir as orientações Minayo (1998), segundo esta, o ponto de partida de uma análise é a compreensão em si da fala e dos textos dos atores investigados.

Nesse sentido, a princípio, buscamos compreender as intencionalidades e os significados presentes nas diretrizes mais gerais da política de Educação Física, Esporte e Lazer. Seguindo os eixos temáticos que nortearam as entrevistas, inicialmente confrontamos os depoimentos dos gestores com as informações documentais, de forma a reconstituirmos o processo de planejamento e elaboração do Programa Segundo Tempo.

Estes procedimentos possibilitaram as primeiras aproximações das problemáticas significativas que influenciaram a construção da entrevista. Partindo do 
pressuposto de que as tônicas do programa em foco não "falam por si", sendo passíveis de interpretações e ressignificações, buscamos apreender os significados atribuídos às mesmas pelos atores entrevistados. Para isso, organizamos as percepções dos gestores em grupos de tendências, através das quais tentamos analisar suas relações com concepções de Educação Física e propostas de políticas públicas no setor.

Programa Segundo Tempo: Um Olhar Científico para Esta Prática na Formação da Criança e do adolescente.

[...] saberes produzidos e/ou transmitidos, em sua dinamicidade, efetivamente, tenham a responsabilidade de cultivar teorias e desenvolver práticas abertas, racionais, críticas, reflexivas, autocríticas, aptas a se auto reformar, que venham subsidiar situações ao aprendente e ao ensinamento para solucionar problemas no cotidiano. Teorias enraizadas à luz de paradigmas que permitam tratar o conhecimento complexo, perspectivando um processo de base para os enfrentamentos socioculturais, em que as emoções, prazeres e dignidade da pessoa em viver momentos de liberdade pelo domínio de práticas, produzam experiências de fluxo por lidar com desafios, resolver problemas e/ou descobrir algo novo, condições que faltam com mais frequência no tempo livre (FRANÇA, 2005, p.42).

Nos últimos anos o Programa Segundo Tempo vem sendo utilizado como estratégias nos mais variados contextos, entre eles: o escolar, o organizacional, o esportivo e o comunitário. Nessa perspectiva entende-se a política pública como uma opção na possibilidade de transformação social e na inversão de valores sociais, que possivelmente esteja associada à constatação, por parte da nossa sociedade, de que, nossas formas de vida coletivas necessitam ser reequilibradas, e que a realização de atividades sistemáticas através de um programa social como o Segundo Tempo, coloca elementos fundamentais para a consolidação desta transformação, tal como levanta Broto:

[...] joga-se para superar desafios e não para derrotar os outros; joga-se para gostar do jogo, pelo prazer do jogo. São jogos onde o esforço cooperativo é necessário para se atingir um objetivo comum e não para fins mutuamente exclusivos (BROTTO, 2001, p. 54).

O Programa Segundo Tempo tem em sua essência o aperfeiçoamento na aceitação, no envolvimento e na diversão e que tem como propósito mudar as características de exclusão, seletividade, agressividade e exacerbação da competitividade, predominantes na sociedade e nos jogos tradicionais, "o objetivo primordial é criar oportunidades para o aprendizado cooperativo e interação cooperativa prazerosa" (BROTTO, 2001, p.123).

Reconhecendo a relevância do esporte enquanto fenômeno e sua potencialidade são estruturados como intuito de diminuir a pressão excessiva para a exclusão, onde $\mathrm{o}$ individualismo torna-se mais importante que a cooperação, sendo assim o Programa Segundo Tempo, vem intencionalmente romper com essas barreiras historicamente estabelecidas e a interação e a participação de todos, deixando externar a espontaneidade e a alegria nas práticas de esporte.

Discutindo sobre o tema jogo, Brotto (2001) ressalta que os jogos, em sua grande maioria, estimulam o confronto e não o encontro, enfatizando o resultado numérico e a vitória, o que produz mais perdedores do que vencedores, eliminando as pessoas e a diversão, criando espaços de tensão e ilusão, não deixando opção ou outras oportunidades de escolha.

Barreto (2006) evidencia que não é somente através da prática esportiva que os beneficiários passarão a ser cooperativas, pois existem fatores sócio-político-econômicos que estruturam competitivamente a sociedade capitalista. Entretanto, aponta para a possibilidade de mudanças na própria estrutura social. Para isso, seria necessário iniciar a aprendizagem cooperativa com as crianças pequenas, pois, quando são estimuladas a inversão de valores se estabelece culturalmente, ocorre um aumento de interação social e promoção de atitudes refletidas entre os participantes do programa.

A partir da fala dos atores entrevistados, foi possível destacar alguns princípios trabalhados que são fundamentais para a consolidação dessa mudança de perspectiva discutida ao longo do trabalho:

1. A inclusão: trabalhar com as pessoas procurando ampliar a participação e a integração entre elas nos processos em curso; 
Exemplo: numa situação pedagógica em que vivenciamos a prática da atividade é importante que os alunos reconheçam que todos deverão participar mesmo aqueles que possuam algum tipo de limitação, pois a prática da Educação Física não se restringe aos mais aptos.

2. A coletividade: as conquistas e ganhos somente se realizam coletivamente, reconhecendo a individualidade de cada um;

Exemplo: na prática das atividades é relevante que os alunos observem de maneira crítica que todos possuem potencialidades e fraquezas, e que em conjunto podem ser superadas ou somadas através de uma ajuda simultânea, resultando em conquistas coletivas.

3. Igualdade de direitos e deveres: a participação e a responsabilidade são asseguradas pela decisão, gestão e a repartição justa dos benefícios promovidos pela atividade cooperativa;

Exemplo: através da prática das atividades os beneficiários aprendem a respeitar regras (deveres) e exigi-las quando necessárias (direitos), tornando isso uma prática que condiciona seu comportamento, auxiliando na vida em sociedade, uma vez que todo cidadão tem direitos e deveres a serem cumpridos.

4. Desenvolvimento humano: o objetivo último da experiência da atividade sistemática é o ser humano e o seu aprimoramento;

Exemplo: a atividade esportiva corrobora para o desenvolvimento do caráter, autonomia e criticidade das crianças e do adolescente, pois mesmo em situações adversas as crianças são induzidas a lidar com questões com derrota e vitória, aspectos esses que não se resumem apenas a sua participação e contribuição nos resultados.

5. Processualidade: no desenvolvimento das atividades é privilegiado o processo os meios e não os fins;

Exemplo: Numa situação pedagógica em que vivenciamos a prática de atividades é importante que os alunos reconheçam que todos deverão participar mesmo aqueles que possuam algum tipo de limitação, pois a prática da Educação Física não se restringe aos mais aptos. (SOLER, 2006).

Diante do exposto, acreditamos que um dos objetivos do esporte educacional deve ser fazer com que os beneficiários aprendam a tratar o cotidiano das atividades por meio das diferentes dimensões.

Partindo desse enfoque a atividade corporal, compreendendo-a de modo mais amplo, conferindo-Ihe maior abrangência, quando de sua utilização no esporte educacional, poder-se-ão obter melhores condições e oportunidade de oferecer aos que a praticam inúmeras formas de se trabalhar as manifestações culturais de modo mais leve, mais espontâneo, mais criativo.

Dentro dessa compreensão, possibilita a maior valorização de elementos lúdicos da cultura, alcançando uma formação mais crítica e criativa do homem. É no brincar, e somente no brincar, que o indivíduo, a criança ou o adulto pode ser criativo e utilizar sua personalidade integral: e é somente sendo criativo que o homem conhece seu eu (WINNICOTT, 1975, p.80).

Os entrevistados corroboram a relevância da ludicidade, do brincar, na grande maioria das entrevistas realizadas como algo muito relevante/importante no PST, tais dados se somam as análises aqui feitas e inserem-se no processo da construção do conhecimento de si mesmo dos que participam do Programa.

Ao tratar conteúdos com ludicidade nas práticas dentro do universo do Programa Segundo Tempo, o professor estará proporcionando um ambiente de socialização, cooperação e autoconhecimento a seus beneficiários, onde a criatividade se encontra presente no cotidiano, transformando esse espaço em um lugar de encontro humano.

Um Programa de políticas públicas com esse olhar tem maior possibilidade de atender as necessidades de seus beneficiários, uma vez que estando esses desprovidos da necessidade de competir, de se firmar em posições de destaque, vivenciam um comportamento que os leva a se colocarem de maneira natural de frente as propostas que o professor apresenta, agindo assim com naturalidade. Dentro desse entendimento sobre o exercício de ensinar-aprender, quanto mais espontânea e prazerosa for à atividade, melhores os resultados que seus praticantes obterão.

Certos que um olhar crítico deste universo colabora para uma ação transformadora da ação social e estimula o desejo de aprender, despertando a motivação imprescindível no ato de construção do saber, o que significa realmente educar, entendo ser o programa Segundo Tempo um excelente viés de intervenção social.

\section{CONSIDERAÇÕES FINAIS}

O Programa Segundo Tempo, enquanto uma polí- 
tica pública de esporte que se materializa diretamente com a aprendizagem, mas para que haja um eficiente resultado acerca de todo o procedimento lento de desconstrução de pensamentos e ideias arraigadas nos beneficiários é algo extremamente complexo que exige grande dedicação do professor, transformar as opiniões já estabelecidas pelos mesmo em algo atrativo e interessante é um enorme desafio para uma proposta continuada de política pública de esporte pensada nacionalmente e desenvolvida no município de Jaboatão dos Guararapes, é necessário um conjunto com toda o sistema para repensar com urgência novos caminhos na tentativa de demonstrar para seus alunos a importância da prática esportiva na formação do cidadão.

O processo de motivação requer tempo, dedicação, paciência, atitudes pedagógicas, técnicas, metodológicas e de saberes necessários para se possível construir uma prática consolidada com as partes envolvidas, tanto dos beneficiários, como dos professores, pais e gestores, apesar de que mudanças de percepções formadas neste nível de ensino é uma tarefa um tanto quanto complicada, mas podemos partir do princípio de que estas mudanças ocorram de forma gradual, em parceria entre todos que compõem o universo, para que cada um se conscientize a respeito de seus papeis dentro do processo como um todo, e que a finalidade do processo educacional seja compreendida de forma eficaz, gerando a motivação do professor para que o mesmo transmita a motivação para seus alunos.

$\mathrm{O}$ que se pretendeu nesse artigo foi despertar mais uma inquietação na área da Educação Física e em outras que desejam vir à cooperação, contribuir para um acervo referente ao tema Programa Segundo Tempo e valorizar a utilização de uma ação de transformação como ferramenta social que auxilia na formação de cidadãos, iniciando nas crianças e adolescentes em situação de vulnerabilidade social.

\section{REFERÊNCIAS}

BRASIL. Política Nacional do Esporte. DF, 2005. Disponível em: http://www.esporte.gov.br/arquivos/conseIhoEsporte/legislacao/polNacEsp.pdf. Acesso em: 15 out. 2016.

BARBIĖRI, C. A. O eco de um gol. In: (et al).

Esporte Educacional - uma proposta renovada. Recife: MEE/INDESP, UPE-ESEF, 1996.
BOGDAN, Robert; BIKLEN, Sari. Investigação qualitativa em educação. Porto: Porto Editora, 1994.

BROTTO, Fábio O. Os jogos cooperativos: se o importante é competir, o fundamental é cooperar! Ana Dias. São Paulo: Novada, 2001.

\section{COLETIVO DE AUTORES. Metodologia do ensino da educação física. São Paulo: Cortez, 1992.}

FRANÇA, T. L. Lazer - corporeidade - educação: o saber da experiência cultural em prelúdio. Natal-RN. Tese de Doutorado em Educação. Universidade Federal do Rio Grande do Norte, 2005.

FREIRE, P. Educação como prática da liberdade. Rio de Janeiro: Paz e Terra, 1967.

FREIRE, P. Pedagogia da esperança. Rio de Janeiro: Paz e Terra, 1980.

FREIRE, P. Pedagogia do oprimido. Rio de Janeiro: Paz e Terra, 1983.

LORENZINI, Ana Rita; BARROS, Ana Maria de Barros; SANTOS, Ana Lucia Felix dos. Ministério do Esporte (Org.). Programa Segundo Tempo no agreste de Pernambuco: a ludicidade e a interdisciplinaridade na construção do exercício da cidadania. Maringá: Eduem, 2010.

LÜDKE, Menga; ANDRÉ, Marli E. D. A. Pesquisa em educação: abordagens qualitativas. São Paulo: EPU, 1986.

MINAYO, Maria Cecília de Souza. O desafio do conhecimento: pesquisa qualitativa em saúde. 5. ed. São Paulo: Hucitec-Abrasco, 1998.

SOLER, R. Educação física escolar. Rio de Janeiro: Sprint, 2006.

SOUSA, Eustáquia. et al. Sistema de monitoramento $\&$ avaliação dos programas esporte e lazer da cidade e segundo tempo do ministério de esporte. Belo Horizonte: O lutador, 2010. 


\section{revista educação}

HISTÓRIAS DE TRANSFORMAÇÃO NAS VIDAS DOS USUÁRIOS DO PROGRAMA SEGUNDO TEMPO (PST) DE JABOATÃO DOS GUARARAPES, PERNAMBUCO

Marcus Vinicius Sanchez Lima, Thiago Vasconcellos Modenesi

THOMAS, Jim. Doing critical ethnography. Qualitative research methods. Thousand Oaks: Sage, 1993.

WINNICOTT, D. W. O brincar e a realidade. Trad. J. O. A. Abreu e V. Nobre. Rio de Janeiro: Imago: 1975.

WEBER, Mirian Geralda. Criatividade. Rio de Janeiro: Sprint, 1991. 